\title{
A IMPOSIÇÃO DA GUARDA COMPARTILHADA COMO REGRA NO \\ ORDENAMENTO JURÍDICO BRASILEIRO: UM PARALELO COM A DOUTRINA DA SITUAÇÃO IRREGULAR
}

\author{
Rodrigo Freitas Paixão ${ }^{1}$ \\ Ana Paula Motta Costa ${ }^{2}$
}

\section{Resumo:}

O artigo busca traçar um paralelo entre a imposição da guarda compartilhada pela Lei 13.058/2014 e a Doutrina da Situação Irregular que estabelecia a forma como os direitos das crianças e dos adolescentes eram tutelados pelo Estado antes da Convenção Internacional sobre os Direitos da Criança. Para tanto, mostrará que, apesar da boa intensão do legislador, a imposição incondicional da guarda compartilhada pode configurar uma afronta à Doutrina da Proteção Integral, em especial ao Princípio do Melhor Interesse da Criança e do Adolescente, e um retorno aos principais pensamentos que embasavam a Doutrina da Situação Irregular.

Palavras-chave: direitos humanos de crianças e adolescentes; princípio do melhor interesse da criança e do adolescente; guarda compartilhada; doutrina da situação irregular; doutrina da proteção integral.

\section{THE IMPOSITION OF JOINT CUSTODY AS A RULE IN THE BRAZILIAN LEGAL SYSTEM: A PARALLEL WITH THE IRREGULAR SITUATION DOCTRINE.}

\begin{abstract}
:
The article seeks to draw a parallel between the imposition of shared custody by Law 13.058/2014 and the Irregular Situation Doctrine which established how the rights of children and adolescents were protected by the State prior to the International Convention on the Rights of the Child. This study will demonstrate that, in spite of the good intentions of the legislator, the unconditional imposition of joint custody can constitute an affront to the Integral Protection Doctrine, especially to the Principle of the Best Interests of Children and Adolescents, and a return to the main thoughts that embase the Irregular Situation Doctrine
\end{abstract}

Keywords: human rights of children and adolescents; principle of the best interests of children and adolescents; joint custody; irregular situation doctrine; integral protection doctrine.

\section{INTRODUÇÃO}

A guarda compartilhada foi introduzida no ordenamento jurídico brasileiro pela Lei 11.698/2008, sob o fundamento de ser a modalidade que melhor que respeita os Princípios da

\footnotetext{
${ }^{1}$ Graduado em Direito pela Universidade Luterana do Brasil. Especialista em direito civil com ênfase em família e sucessões pela Faculdade IDC. Mestrando em Direitos Humanos pela UniRitter com bolsa institucional. Advogado

${ }^{2}$ Graduada em Direito pela PUC/RS, Bacharel em Ciências Sociais pela UNISINOS (1990), Pós-graduada em Educação pela UFRGS, Mestre em Ciências Criminais pela PUCRS e Doutora em Direito pela PUCRS. Advogada, professora do programa de Pós-graduação - Mestrado - da Faculdade de Direito da UFRGS e do Centro Universitário Ritter dos Reis
} 
Igualdade de Gênero e da Isonomia Parental, bem como o do Melhor Interesse da Criança e do Adolescente, pois faz com que ambos os genitores exerçam, de forma igual e conjunta, todos os direitos e deveres decorrentes do poder familiar, reduzindo, em comparação com a guarda unilateral, as consequências negativas que o término da relação conjugal causa aos filhos.

Contudo, a partir da interpretação do artigo 1.584, II, $\S 2^{\circ}$ do Código Civil introduzido pela Lei 11.698/2008, estabeleceu-se o entendimento jurisprudencial dominante de que a guarda compartilhada não poderia ser imposta sem o consenso dos genitores e em ambientes litigiosos, pois seu êxito estaria condicionado ao diálogo e ao bom senso. Visando modificar esta interpretação, foi promulgada a Lei 13.058/2014 que, ao alterar a redação do artigo 1.584, II, $\S 2^{\circ}$ do Código Civil, estabeleceu a guarda compartilhada como regra máxima, não podendo ser aplicada apenas nas duas hipóteses legais: quando um dos genitores não estiver apto a exercer o poder familiar, ou manifestar expressamente seu desejo de não querer a guarda do filho para si.

Esse artigo pretende verificar se a alteração feita pela Lei 13.058/2014 pode ser considerada um retrocesso em relação à Doutrina da Proteção Integral e uma afronta ao Princípio do Melhor Interesse da Criança e do Adolescente, na medida em que pode conter elementos objetivos de identificação com a Doutrina da Situação Irregular.

Para tentar resolver esse problema, será feito, por meio de pesquisa bibliográfica, uma análise da Doutrina da Situação Irregular e sua evolução para a Doutrina da Proteção Integral, trabalhando os Princípios da Prioridade Absoluta e do Melhor Interesse da Criança e do Adolescente. Também será exibida a evolução legal dos institutos da guarda e do poder familiar no direito pátrio. Ao final, serão expostos os elementos da Doutrina da Situação Irregular e traçado um paralelo destes com a imposição da guarda compartilhada por meio da Lei 13.058/2014 e apresentadas as conclusões do estudo.

\section{DA DOUTRINA DA SITUAÇÃO IRREGULAR À DOUTRINA DA PROTEÇÃO INTEGRAL}

$\mathrm{Na}$ América Latina, até o início do século XX, o único tratamento legislativo diferenciado dado às crianças e adolescentes dizia respeito à redução da pena em um terço nos crimes cometidos por autores com menos de 18 anos de idade, Esta diferenciação ocorria apenas na aplicação da pena e não no seu cumprimento, pois as crianças e adolescentes eram 
colocados juntos com os adultos nas penitenciárias e, por consequência, submetidos às mesmas condições degradantes de encarceramento e de promiscuidade (MÉNDEZ, 1998, p. 21).

Com o objetivo de reverter esse quadro e proteger esta população infantojuvenil específica, a partir da segunda década do século XX, surgiu na América Latina a Doutrina da Situação Irregular, cujas leis possuíam natureza penal e davam ao Estado, na pessoa do juiz de menores, um poder discricionário ilimitado de tomar as medidas necessárias para proteger as crianças e adolescentes delinquentes e moralmente abandonados, que passaram a receber a denominação jurídica "menores".

Com relação ao termo “menor”, Irma Rizzini ensina que:

Menor não é apenas aquele indivíduo que tem idade inferior a 18 ou 21 anos,
conforme mandava a legislação em diferentes épocas. Menor é aquele que,
proveniente de família desorganizada, onde imperam os maus costumes, a
prostituição, a vadiagem, a frouxidão moral e mais uma infinidade de características
negativas, tem a sua conduta marcada pela amoralidade e pela falta de decoro, sua
linguagem é de baixo calão, sua aparência é descuidada, tem muitas doenças e pouca
instrução, trabalha nas ruas para sobreviver e anda em bandos com companhias
suspeitas. Mesmo que ele não se enquadre na descrição acima, retirada dos
questionários, será sempre um candidato se seus pais não oferecerem "suficientes
garantias de moralidade energia e capacidade econômica" para educá-lo. (1993, p.
96, grifo da autora).

Conforme se depreende da transcrição acima, esse conceito é amplo e não diferencia os menores delinquentes dos menores carentes, considerando todos "menores em situação irregular". Também os separa das "crianças e adolescentes em situação regular", pois estas pertencem às famílias com condições econômicas de atender minimamente suas necessidades (MACHADO, 2003, p. 27 - 33).

Na Doutrina da Situação Irregular, a institucionalização indiscriminada dos menores em situação irregular era a medida mais aplicada pelo Estado, sob a justificativa de que eles estariam mais bem assistidos nas casas de acolhimento do que com suas famílias que não tinham condições econômicas de atender as necessidades deles.

Ou seja, a proteção dada pela Doutrina da Situação Irregular era baseada na visão que os adultos, mais especificamente o juiz de menores, tinham sobre quais medidas protetivas atendiam adequadamente os interesses da população infantojuvenil em situação irregular $^{3}$. De acordo com esta Doutrina, o juiz de menores deveria agir como um bom pai de

\footnotetext{
${ }^{3}$ A Doutrina da Situação Irregular albergava o Princípio do Melhor Interesse da Criança e do Adolescente, incluído na Declaração Internacional dos Direitos das Crianças de 1959 e nas legislações de menores (no Brasil o Código de Menores - Lei 6.697/1979. Antes dele, o Decreto 16.272/1923 e Leis 5.258/1967 e 5.439/1968). Esse
} 
família e, como tal, atuava com amplos poderes, sem a necessidade de, inclusive, observar direitos constitucionais elementares, como o do contraditório e o da ampla defesa, que eram assegurados aos adultos. A decisão adotada por esses juízes era, na absoluta maioria das vezes, a institucionalização destes menores em situação irregular e tinha um viés protetivo e não punitivo (MACHADO, 2003, p. 46-48).

Esse objetivo protetivo da institucionalização dificultava as críticas daqueles que entendiam ser esta uma medida prejudicial, pois como algo que visa proteger os menores em situação irregular, retirando-os das ruas, dos maus exemplos, da delinquência, dando-lhes abrigo e alimentação poderia ser prejudicá-los?

Como bem analisado por Emílio Garcia Méndez (1998, p. 23, grifo do autor), é "paradoxal observar que a falta de limites, garantias e formalidades torna pratica e tecnicamente impossível que o direito de menores seja violado pelos encarregados de sua aplicação".

Com esta ideia de proteção, a Doutrina da Situação Irregular, por meio do conceito amplo de "situação irregular", identificou as crianças e adolescentes nesta situação - os menores - , separando-os dos demais para criar um sistema sócio-penal de proteção, cujo objetivo era, através da institucionalização, controlar esta população infantojuvenil desassistida (os delinquentes e aqueles com potencial para delinquir - os carentes), afastandoa do convívio social e da influência negativa do meio em que estava inserida para que passasse a ser cuidada e educada dentro das casas de acolhimento. Entretanto, este cuidado dentro das instituições era insatisfatório ou inexistente, as crianças e adolescentes eram simplesmente largados e mantidos por tempo indeterminado dentro destes locais.

Emílio Garcia Méndez (1998, p. 24-27) destaca que a Doutrina da Situação irregular foi uma forma do Estado, num momento de crise econômica ${ }^{4}$, em negação à sua deficiente política social e aos direitos fundamentais básicos do ser humano, mais especificamente das crianças e adolescentes, judicializar um problema social, passando a ter o poder de agir indiscriminadamente sobre aqueles indivíduos classificados juridicamente como menores, editando medidas que privilegiavam o afastamento destes das suas famílias e da sociedade.

princípio era aplicado sob o enfoque dos adultos, ou seja, com base naquilo que eles entendiam ser o melhor para os menores em situação irregular (COSTA, 2012, p. 152-153).

4 Durante o século XX todos os países da América Latina enfrentaram agraves crises econômicas que aumentaram a taxa de desemprego e, consequentemente, o número de menores em situação irregular. 
A Doutrina Jurídica da Proteção Integral veio justamente para acabar com os equívocos conceituais e procedimentais da Doutrina da Situação Irregular, tendo como base a Convenção Internacional dos Direitos da Criança ${ }^{5}$. No Brasil, além desta Convenção, a Doutrina também é composta pela Constituição Federal de 1988 (prevê em seus artigos 227 e 228 direitos fundamentais de crianças e adolescentes) e pelo Estatuto da Criança e do Adolescente (ECA - Lei 8.069/1990).

Esta Doutrina acabou com a diferenciação entre "menores em situação irregular" e "crianças em situação regular", adotando a concepção de que toda a criança, independentemente da classe social, está em processo de desenvolvimento e é sujeito de direitos cuja proteção e efetivação são prioritários em relação aos demais cidadãos e de responsabilidade da família, da sociedade e do Estado, compondo um sistema de proteção. (AMIN, 2015, p. 50).

Seus pilares são o Princípio da Prioridade Absoluta e o Princípio do Melhor Interesse da Criança e do Adolescente. O Princípio da Prioridade Absolta está disposto no artigo 227 da Constituição Federal $^{6}$ e nos artigos $4^{\circ}$ e 100, parágrafo único, inciso II, ambos do Estatuto da Criança e do Adolescente e visa a efetivação dos direitos fundamentais das crianças e adolescentes, por meio da sua prevalência, tanto na esfera pública como na privada, sobre os direitos dos adultos e do Estado (AMIN, 2015. p. 62). Busca também equilibrar as desigualdades entre adultos e crianças, estabelecendo uma equiparação jurídica material entre esses sujeitos de direitos (MACHADO, 2003, p. 119). Portanto, está menos ligado à discussão jurídica sobre a guarda compartilhada (objeto deste estudo) e mais à primazia que deve ser dada pelo Estado às políticas sociais públicas que buscam a proteção e a efetivação dos direitos fundamentais da população infantojuvenil.

O Princípio do Melhor Interesse da Criança e do Adolescente, com a redação dada pelo artigo 3.1 da Convenção Internacional dos Direitos da Criança ${ }^{7}$, recebe um significado inverso do que lhe era dado pela Doutrina da Situação Irregular e passa a ser aplicado com

\footnotetext{
${ }^{5}$ Realizada pela Assembleia Geral das Nações Unidas em 20 de novembro de 1989, ratificada pelo Brasil e inserida integralmente no sistema normativo por meio do Decreto 99.710, de 21 de novembro de 1990.

${ }^{6}$ Nos termos do artigo 227 da Carta Magna, "é dever da família, da sociedade e do Estado assegurar à criança, ao adolescente e ao jovem, com absoluta prioridade, o direito à vida, à saúde, à alimentação, à educação, ao lazer, à profissionalização, à cultura, à dignidade, ao respeito, à liberdade e à convivência familiar e comunitária, além de colocá-los a salvo de toda forma de negligência, discriminação, exploração, violência, crueldade e opressão". (BRASIL, 1988)

7 "Art. 3.1: Todas as ações relativas às crianças, levadas a efeito por instituições públicas ou privadas de bem estar social, tribunais, autoridades administrativas ou órgãos legislativos, devem considerar, primordialmente, o interesse maior da criança”. (BRASIL, 1990).
} 
base no que é melhor para a criança e adolescente na perspectiva destes e não na dos adultos, como ocorria na Doutrina da Situação Irregular.

Embora também sirva como norte para todas as ações do Poder Público, esse princípio tem maior destaque e aplicabilidade no direito de família, tanto no exercício do poder familiar pelos pais - paternidade responsável - como nas demandas judiciais onde se discute guarda, convivência e alimentos em favor dos filhos. (PEREIRA, Rodrigo, 2012, p. $150,154-155)$.

Nos casos de judicialização, Sergio Luiz Kreuz (2012, p. 74) destaca que esse princípio:

Serve como um importante elemento de solução de conflitos em relação à criança, buscando-se sempre o que lhe for mais favorável ao seu desenvolvimento", devendo ser entendido "como norma, como imperativo, para a concretização de todos os direitos assegurados às crianças e adolescentes.

O autor alerta que, em face do seu "conteúdo amplo de indeterminado, certamente, nem sempre será fácil de, no caso concreto, desvelar o alcance e em que realmente consiste" esse princípio, destacando a importância da atuação de uma equipe multidisciplinar para que a decisão do juiz não se atenha apenas a questões jurídicas (2012, p. 73).

Trata-se de um princípio de aplicação cogente em função da ratificação da Convenção Internacional dos Direitos da Criança pelo Decreto 99.710/90 e de natureza especial, devendo ser considerado elemento acessório na utilização da norma. Para sua aplicação, os operadores do direito devem sempre fazer a análise atenta de cada caso e com base em uma interpretação sistemática das normas que tratam do direito infantojuvenil, em especial as constitucionais, internacionais e especiais (PEREIRA, Tânia, 2008, p. 25, 44 e 48).

Segundo Miguel Cillero Buñol (2001, p. 101-105), o Princípio do Melhor Interesse da Criança e do Adolescente, como todos os demais, é oriundo de uma legislação e, portanto, sua efetivação deve ocorrer por meio da satisfação dos direitos positivados, mas não com base em algo que esteja além da lei, sob pena de se retornar à absoluta discricionariedade da autoridade administrativa e/ou judicial que imperava na Doutrina da Situação Irregular.

Flávio Guimarães Lauria (2003, p. 62) acrescenta o "aspecto adjetivo" do princípio em estudo. De acordo com o autor, para o respeito total desse princípio, não basta que a decisão seja proferida com base nele, é preciso que, na prática, seu cumprimento seja efetivado de forma a preservar o interesse das crianças e adolescentes envolvidos, mesmo após a decisão judicial. 
Diferentemente do que ocorre com o Princípio da Prioridade Absoluta que tem natureza constitucional (artigo 227 da Carta Magna), a doutrina e a jurisprudência divergem com relação ao status legal atribuído ao Princípio do Melhor Interesse da Criança e do Adolescente, pois esse decorre de um tratado internacional. O entendimento majoritário ${ }^{8}$ é de que as regras e princípios neles contidos, mesmo quando integrados ao sistema normativo brasileiro na forma do artigo $5^{\circ}, \S 2^{\circ}$ da Constituição Federal ${ }^{9}$, possuem valor de norma constitucional.

Contudo, ao julgar o RE 466.343-1/SP, o Supremo Tribunal Federal fixou entendimento que apenas os tratados albergados pelo Brasil nos termos do artigo $5^{\circ}, \S^{\circ}$ da Carta Magna ${ }^{10}$ possuem status de norma constitucional. Todos aqueles que não tenham sido aprovados na forma prevista no artigo $5^{\circ}, \S 3^{\circ}$ da Constituição Federal possuem força de norma supralegal, ou seja, topologicamente situados acima das leis ordinárias e apenas abaixo da Carta Magna.

Independentemente desta discussão, ambos entendimentos colocam o Princípio do Melhor Interesse da Criança e do Adolescente acima das normas do Código Civil, incluindo as introduzidas pela Lei 13.058/2014 e sobre as quais se busca traçar um paralelo com a Doutrina da Doutrina da Situação Irregular.

Assim, o Princípio da Prioridade Absoluta e o Princípio do Melhor Interesse da Criança e do Adolescente, com natureza de direito humanos e previsto expressamente na Constituição Federal e Convenção internacional da qual o Brasil é signatário, devem embasar as ações do Estado em todos os seus Poderes, tanto nas políticas públicas sociais aplicadas pelo Executivo, como na criação de leis pelo Legislativo e nas decisões dos operadores do direito ao aplicar as normas aos casos concretos.

\section{A GUARDA DE FILHOS NO ORDENAMENTO JURÍDICO BRASILEIRO}

\footnotetext{
${ }^{8}$ Sustentado por autores como Valério de Oliveira Mazzuoli (2011, vol. IV, p. 50-70) e Flávia Piovesan (2006,p. 51-77).

$9 \S 2^{\circ}$ Os direitos e garantias expressos nesta Constituição não excluem outros decorrentes do regime e dos princípios por ela adotados, ou dos tratados internacionais em que a República Federativa do Brasil seja parte. (BRASIL, 1988).

${ }^{10} \S 3^{\circ}$ Os tratados e convenções internacionais sobre direitos humanos que forem aprovados, em cada Casa do Congresso Nacional, em dois turnos, por três quintos dos votos dos respectivos membros, serão equivalentes às emendas constitucionais. (BRASIL. 1988).
} 
Para se fazer uma análise do instituto da guarda de filhos é necessário trabalhar também o instituto do poder familiar, pois, embora a guarda não seja da essência do poder familiar, pertence a sua natureza (MOURA, 1980, p. 17) ${ }^{11}$.

Em face disso e para compreender a evolução da guarda unilateral para a compartilhada e sua colocação como a regra máxima, pertinente se fazer um breve histórico da evolução desses institutos do direito brasileiro, diretamente ligado às mudanças sociais, culturais e aos avanços da doutrina e da legislação internacional na área de proteção dos direitos humanos, incluindo, evidentemente, os direitos das crianças e adolescentes.

O Código Civil de 1916 foi feito sob a égide de uma sociedade patriarcal, onde a família era vista como uma entidade econômica mantida em razão da patria potestas ${ }^{12}$ e o papel da mulher era servir o marido e criar os filhos, enquanto o do genitor era trabalhar para prover o sustento familiar. Diante desta realidade sociocultural, já com a alteração dada pela Lei 4.121/1962, estabelecia que na constância do casamento, o denominado pátrio poder era exercido pelo homem com o auxílio da mulher, situação que permanecia inalterada em caso de desquite. No caso da guarda dos filhos, havendo o término da relação afetiva, a vontade dos genitores deveria ser respeitada ou, não havendo consenso, ser concedida ao cônjuge não responsável pelo término da relação, tido por inocente. Sendo ambos responsáveis, a guarda era dada à genitora. O juiz poderia estabelecer a guarda dos filhos de forma diversa da acordada pelos pais, inclusive, concedendo-a a outra pessoa.

A Lei 6.515/1977 introduziu o divórcio e modificou um pouco a forma do estabelecimento da guarda dos filhos após o término da relação, acrescentando que, já havendo separação de fato, ela deveria ser concedida ao genitor com quem o filho estivesse morando.

Promulgado na vigência da Constituição Federal de 1988, do Estatuto da Criança e do Adolescente e da Convenção Internacional dos Direitos da Criança, o Código Civil de 2002 trouxe modificações significativas nos institutos do pátrio poder e da guarda.

O pátrio poder deu lugar ao poder familiar que, em função dos Princípios da Igualdade de Gênero e da Isonomia Parental (artigos 5, I, 226, § 5 e 229 da Carta Magna)

\footnotetext{
${ }^{11}$ A guarda poder ser destacada do poder familiar, como ocorre na modalidade unilateral ou quando ela é concedida a terceiros, mas sem que, necessariamente, os pais percam o poder familiar.

${ }^{12} \mathrm{O}$ patria potestas é o amplo poder concedido ao homem, pater familias, sobre os filhos e a esposa que lhe deviam obediência e respeito.
} 
passou a ser exercido igualmente por ambos os genitores durante e após o término da união afetiva.

Já com relação à guarda dos filhos, o Código Civil de 2002 manteve a autonomia da vontade dos genitores e estabeleceu que, em caso de divergência, a guarda seria atribuída aquele que mostrasse ter melhores condições de ser o guardião. Foi mantido o poder do magistrado de forma diversa da acordada e de concedê-la a outro parente caso nenhum dos pais tenha condições de ser o guardião.

Posteriormente, a Lei 11.698/2008 introduziu a guarda compartilhada no ordenamento jurídico brasileiro e estabeleceu que ela deveria ser estabelecida "sempre que possível". Esta Lei preservou a orientação anterior com relação a qual genitor deveria exercer a guarda unilateral no caso de inviabilidade da forma compartilhada.

A Lei 13.058/2014 estabeleceu a guarda compartilhada como regra máxima do ordenamento jurídico brasileiro, prevendo no artigo 1.584 , inciso II, $\S 2^{\circ}$ os dois únicos casos em que ela não será aplicada pelo juiz: quando um dos genitores não estiver apto a exercer o poder familiar, ou quanto um deles "declarar ao magistrado que não deseja a guarda do menor". Em todas as demais hipóteses, mesmo sem o consenso dos pais, a Lei dispõe que o juiz deverá estabelecer a guarda compartilhada. Quanto ao poder familiar, reforçou sua imutabilidade independentemente da situação conjugal ou modalidade de guarda.

A preferência pela guarda compartilhada está baseada em 3 princípios: Igualdade de Gênero, Isonomia Parental e Melhor Interesse da Criança e do Adolescente.

O Princípio da Igualdade de Gênero decorre da legislação internacional que versa sobre direitos humanos, está disposto no artigo $5^{\circ}$, I da Constituição Federal e veda qualquer tipo de discriminação em função de gênero. Ou seja, não é mais constitucionalmente admissível que, conforme previa o Código Civil de 1916, a guarda dos filhos seja deferida com base no sexo dos genitores.

O Princípio da Isonomia Parental resulta do Princípio da Igualdade de Gênero e está disposto nos artigos 226, $\$ 5^{\circ}$ e 229 da Carta Magna, segundo os quais, independente do gênero, da situação conjugal e da modalidade de guarda dos filhos, o poder familiar dos pais permanece inalterado.

Esse princípio é resultado do ingresso da mulher no mercado de trabalho e da consequente necessidade do homem assumir diretamente a função parental que antes era só da genitora, participando mais ativamente, às vezes até mais do que ela, nos cuidados e educação 
dos filhos. A família patriarcal e o mito do amor materno ${ }^{13}$ cedem lugar à família eudemonista, onde homem e mulher gerenciam a entidade familiar em conjunto e em igualdade de condições, contribuindo para o sustento do lar e participando igualmente na criação e educação da prole.

Quanto ao Princípio do Melhor Interesse, esse está relacionado a questões afetivas e emocionais, pois na guarda compartilhada, diferentemente do que ocorre na unilateral, além de uma convivência mais ampla, as decisões são debatidas e tomadas pelos genitores de forma conjunta, proporcionando o contraponto e garantindo que a definição ocorra de forma a melhor atender o interesse dos filhos (GRISARD FILHO, 2016, p. 137). Esta característica da guarda compartilhada reduz os efeitos negativos do término das relações afetivas, mantendo a união e a colaboração dos genitores, ao menos com relação às questões da prole.

O respeito a esses princípios foi o que embasou a Lei 11.698/2008, cujo objetivo era introduzir a guarda compartilhada no ordenamento jurídico brasileiro e modificar a ideia que o genitor guardião (na maioria absoluta das vezes a mãe, em face do mito do amor materno) exercia exclusivamente o poder familiar, cabendo ao não guardião apenas o direito de conviver esporadicamente com o filho e fiscalizar o exercício do poder familiar.

Quanto ao exercício exclusivo do poder familiar pelo genitor guardião, importante destacar que embora, legalmente, a situação conjugal e a modalidade da guarda não tragam qualquer consequência ao pleno exercício do poder familiar pelos genitores, a guarda unilateral provoca, faticamente, uma perda significativa dessa autoridade (SILVA, 2002, p. 66-67), pois a cultura social e jurídica do Brasil entende que o genitor guardião tem mais autoridade sobre o filho que o não guardião ${ }^{14}$. Conforme ensina Patrícia Pimentel de Oliveira Chambers Ramos, na guarda unilateral prevalece sempre a decisão do genitor guardião, cabendo ao não guardião, em caso de divergência, buscar o Poder Judiciário para solucionar o impasse (2016, p. 105-106).

Entretanto, a interpretação que os Tribunais passaram a dar à expressão "sempre que possível" do artigo 1.584, inciso II, $\S 2^{\circ}$ do Código Civil, introduzido pela Lei 11.698/2008,

\footnotetext{
${ }^{13}$ Com relação ao mito do amor materno, ver a obra de Elizabeth Badinter (1995). Segundo a autora, o amor não é um sentimento inerente a todas as mulheres, mas construído e desenvolvido de acordo com questões sociais e econômicas históricas.

${ }^{14}$ Gustavo Tepedino (2004, p. 321) observa que, embora a guarda compartilhada no ordenamento jurídico brasileiro não traga qualquer alteração legal em função da imutabilidade do poder familiar, "contribui para a recuperação de uma apreciação ética das relações de filiação, de modo absolutamente necessário e complementar ao exercício conjunto da autoridade parental". No mesmo sentido, Waldyr Grisard Filho (2016, p. 202) refere esta Lei como um "instrumento pedagógico para infirmar o senso comum vigente e desenvolver o efetivo exercício do poder familiar a ambos os genitores".
} 
restringiu significativamente a aplicação da guarda compartilhada nas demanda judiciais, pois a jurisprudência limitou a aplicação desta modalidade de guarda às demandas consensuais, entendendo não ser possível a imposição judicial da guarda compartilhada em um ambiente litigioso onde os genitores não são capazes de estabelecer um diálogo referente às questões ligadas à criação e educação dos filho, sob pena de acirrar o conflito e causar ainda mais prejuízos à prole ${ }^{15}$.

Esta interpretação jurisprudencial gerou um grande movimento dos operadores do direito favoráveis à guarda compartilhada, que argumentaram ser um equívoco condicionar sua aplicação ao consenso, pois o dissenso dos genitores está presente em todas demandas que versam sobre a guarda e se houvesse consenso eles não estariam litigando. Acrescentaram ainda que esse condicionamento torna morta a letra da lei e premia o genitor que busca o litígio para evitar compartilhar a guarda do filho com o outro (GRISARD FILHO, 2016, p. 198; ANDRIGHI, 2011; ROSA, 2015, p. 82-83).

Esse movimento deu origem à Lei $n^{\circ} 13.058 / 2014$ que, conforme se observa na justificação contida no seu projeto de lei (PL n ${ }^{\circ}$ 1.009-B/2011) de autoria do Deputado Federal Arnaldo Faria de Sá, abaixo transcrita, veio para alterar o texto do artigo 1.584, inciso II, $\$ 2^{\circ}$ do Código Civil ${ }^{16}$ (dado pela Lei $n^{\circ} 11.698 / 2008$ ) e modificar o entendimento jurisprudencial sobre a aplicação da guarda compartilhada, estabelecendo esta modalidade como regra máxima no ordenamento jurídico brasileiro e somente não poder ser aplicada nas duas hipóteses expressas na nova redação deste dispositivo legal ${ }^{17}$ (quando um dos genitores não estiver apto a exercer o poder familiar, ou manifestar expressamente não querer a guarda para si. Segundo consta na justificativa deste Projeto de Lei:

${ }^{15}$ Ementa: DISSOLUÇÃO DE UNIÃO ESTÁVEL. GUARDA COMPARTILHADA. DESCABIMENTO. ALIMENTOS. FILHO MENOR. ADEQUAÇÃO DO QUANTUM. 1. A chamada guarda compartilhada não consiste em transformar o filho em objeto, que fica a disposição de cada genitor por um determinado período, mas uma forma harmônica ajustada pelos genitores, que permita ao filho desfrutar tanto da companhia paterna como da materna, num regime de visitação amplo e flexível, mas sem que o filho perca seus referenciais de moradia. 2. Para que a guarda compartilhada seja possível e proveitosa para o filho, é imprescindível que exista entre os pais uma relação marcada pela harmonia e pelo respeito, onde não existam disputas nem conflitos; mas, quando o litígio é uma constante, a guarda compartilhada é descabida 3. Os alimentos devem ser fixados de forma a atender as necessidades do alimentado, mas dentro das possibilidades do alimentante e sem sobrecarregá-lo em demasia. Recurso parcialmente provido. (Apelação Cível No 70059147280, Sétima Câmara Cível, Tribunal de Justiça do RS, Relator: Sérgio Fernando de Vasconcellos Chaves, Julgado em 16/04/2014)

${ }^{16}$ Artigo 1.584, inciso II, $\S 2^{\circ}$ : "Quando não houver acordo entre a mãe e o pai quanto à guarda do filho, será aplicada, sempre que possível, a guarda compartilhada. (Incluído pela Lei no 11.698, de 2008)". (BRASIL, 2002)

${ }_{17}$ Artigo 1.584, inciso II, $\S 2^{\circ}$ : "Quando não houver acordo entre a mãe e o pai quanto à guarda do filho, encontrando-se ambos os genitores aptos a exercer o poder familiar, será aplicada a guarda compartilhada, salvo se um dos genitores declarar ao magistrado que não deseja a guarda do menor. (Redação dada pela Lei no 13.058 , de 2014)". (BRASIL, 2002). 
Muito embora não haja o que se negar sobre avanço jurídico representado pela promulgação da Lei $\mathrm{n}^{\circ} 11.698$, de 13.06.08, a qual institui a Guarda Compartilhada no Brasil. Muitas pessoas, inclusive magistrados, parecem não ter compreendido a real intenção do legislador quando da elaboração de tal dispositivo.

Obviamente, para os casais que, sabiamente, conseguem separar as relações de parentesco "marido / esposa" da relação "Pai / Mãe", tal Lei é totalmente desnecessária, portanto, jamais poderiam ter sido tais casais (ou ex-casais) o alvo da elaboração da lei vez que, por iniciativa própria, estes já compreendem a importância das figuras de Pai e Mãe na vida dos filhos, procurando prover seus rebentos com a presença de ambas. Ocorre que alguns magistrados e membros do ministério público, têm interpretado a expressão "sempre que possível" existente no inciso em pauta, como "sempre que os genitores se relacionem bem". Ora nobres parlamentares, caso os genitores, efetivamente se relacionassem bem, não haveria motivo para o final da vida em comum, e ainda, para uma situação de acordo, não haveria qualquer necessidade da criação de lei, vez que o Código Civil em vigor a época da elaboração da lei já permitia tal acordo. Portanto, ao seguir tal pensamento, totalmente equivocado, teria o Congresso Nacional apenas e tão somente desperdiçado o tempo e dinheiro público com a elaboração de tal dispositivo legal, o que sabemos, não ser verdade. Mas, a suposição de que a existência de acordo, ou bom relacionamento, entre os genitores seja condição para estabelecer da guarda compartilhada, permite que qualquer genitor beligerante, inclusive um eventual alienador parental, propositalmente provoque e mantenha uma situação de litígio para com o outro, apenas com o objetivo de impedir a aplicação da guarda compartilhada, favorecendo assim, não o melhor interesse da criança, mas os seus próprios, tornando inócua a lei já promulgada.

Embora refira expressamente apenas o Princípio do Melhor Interesse da Criança, esta justificação deixa claro também a preocupação do legislador de colocar a guarda compartilhada como regra para possibilitar que ambos os genitores continuem a exercer o poder familiar após do término da relação afetiva, o que vai ao encontro dos Princípios da Igualdade de Gênero e da Isonomia Parental.

É possível ainda extrair desta justificação, bem como do posicionamento doutrinário favorável à imposição judicial da guarda compartilhada mesmo em caso de dissenso, que a Lei 13.058/2014 busca reduzir a litigiosidade entre o casal na medida que retira da disputa a questão da guarda, o que acaba, em tese, beneficiando o filho que passa a conviver em um ambiente menos beligerante.

Ou seja, por respeitar os Princípios da Igualdade de Gênero e da Isonomia Parental, a guarda compartilhada acaba atendendo o Princípio do Melhor Interesse da Criança e do Adolescente, pois, teoricamente, diante da impossibilidade da continuação da relação afetiva dos genitores, é mais benéfico para os filhos a manutenção de uma convivência satisfatória com ambos os pais e que esses continuem a decidir conjuntamente as questões relativas à sua criação e educação.

\section{A IMPOSIÇÃO JUDICIAL DA GUARDA COMPARTILHADA E O PARALELO COM A DOUTRINA DA SITUAÇÃO IRREGULAR}


O tema desse estudo é verificar se a Lei 13.058/2014, especificamente o artigo 1.584, inciso II, $\S 2^{\circ}$ do Código Civil pode ser considerado um retrocesso em relação à Doutrina da Proteção Integral por contar com elementos objetivos de identificação com a Doutrina da Situação Irregular.

Para tanto, é necessário traçar um paralelo entre a imposição judicial da guarda compartilhada e os quatro elementos da Doutrina da Situação Irregular na concepção de Emílio Garcia Méndez (1998, p. 27-28). Primeiro elemento: diferentemente da produção teórica das outras leis, feitas por pessoas que não pertencem ao sistema judicial, nem estão ligadas à sua aplicação, as que compõem a Doutrina da Situação Irregular foram construídas com o auxílio de quem tinha "responsabilidade institucional direta em sua aplicação". Segundo elemento: esta Doutrina criou um mito "da excelência dos seus ideais, desvirtuados pela prática". Terceiro elemento: ela se manteve forte durante quase todo do século XX pelo "eufemismo" e "não-entendimento das consequências reais da sua aplicação". Quarto elemento: a existência de "outras funções, distintas das declaradas" que ajudam a manter esta Doutrina e a classificação de menores em situação irregular.

Quanto ao primeiro elemento, conforme já exposto, a guarda compartilhada foi introduzida no ordenamento jurídico brasileiro por meio da Lei 11.698/2008 e, em função do entendimento jurisprudencial no sentido de não ser possível a sua aplicação em um ambiente litigioso onde os genitores buscam a guarda unilateral do filho para si, foi feito um movimento dos operadores de direito contrários a esta posição dos Tribunais que resultou na Lei 13.058/2014, cujo projeto de lei fora apresentando menos de 3 anos depois da promulgação da Lei $11.698 / 2008^{18}$. Ou seja, assim como as leis que compunham a Doutrina da Situação Irregular, a Lei 13.058/2014 foi elaborada com base no pensamento de pessoas diretamente interessadas na sua aplicação, juristas especializados no direito de família.

Com relação ao segundo elemento, aqueles que defendem a aplicação da guarda compartilhada nos termos da Lei 13.058/2014 partem do entendimento que esta modalidade, mesmo quando há forte litígio entre os genitores, além respeitar os Princípios da Igualdade de Gênero e da Isonomia Parental, também atende o Princípio do Melhor Interesse da Criança e do Adolescente. Contudo, trata-se de uma presunção que não pode ser aplicada em todos os casos, pois pode existir situações que, em função do exacerbado litígio e da absoluta

\footnotetext{
${ }^{18}$ A Lei 11.698/2008 foi promulgada em 13 de junho de 2008 e o Projeto de Lei ( $\mathrm{n}^{\circ}$ 1.009-B/2011) foi apresentado em 12 de abril de 2011.
} 
impossibilidade de condição de diálogo, seja melhor estabelecer a guarda unilateral, ao menos até que os pais tenham condições de compartilhar a guarda. A Doutrina da Situação Irregular também determinava a institucionalização partindo do pressuposto que esta medida era a que melhor atendia o interesse dos menores, pois eles estariam mais bem assistidos nas casas de acolhimento do que vivendo num ambiente propício à delinquência e/ou sob os cuidados de famílias sem condições econômicas de suprir suas necessidades.

No que tange ao terceiro elemento, embora a Lei 13.058/2014 seja recente e, portanto, não se possa falar em manutenção de um pensamento por um longo período de tempo, o fato da guarda compartilhada ser imposta com base numa presunção de ser a modalidade mais adequada ao Princípio do Melhor Interesse da Criança e do Adolescente conduz à falta de compreensão sobre as reais consequências que sua imposição pode trazer à criança. Embora se possa admitir que, na maior parte dos casos, a guarda compartilhada seja a modalidade mais benéfica, a possibilidade dela ser prejudicial em outros não pode ser ignorada ou, pior, aceita em benefício da maioria. Na Doutrina da Situação Irregular, durante quase um século, com base na ideia de que a institucionalização era a medida mais adequada, ignorou-se a possibilidade dela poder ser contrária aos interesse superior dos menores, o que, posteriormente, concluiu-se ser verdadeiro, culminando com o fechamento de diversas casas acolhimento em todo o Brasil com a entrada em vigor no Estatuto da Criança e do Adolescente.

Por fim, o quarto elemento da Doutrina da Situação Irregular que permite traçar um paralelo com a imposição da guarda compartilhada diz respeito à possibilidade desta imposição buscar não apenas atender os princípios referidos, mas suprir, pela eliminação da discussão a respeito da guarda dos filhos, a incapacidade do Estado de prestar a devida assistência psicológica às famílias, ajudando os genitores a separar conjugalidade da parentalidade para que possam agir em conjunto e em benefício dos filhos. No caso da Doutrina da Situação Irregular, procurou-se, por meio da institucionalização, resolver o problema da incapacidade do Estado de solucionar a questão da delinquência e da pobreza infantojuvenil, retirando esta população das ruas e do convívio social.

Outro paralelo que pode ser feito, e que não diz respeito aos elementos da Doutrina da Situação Irregular acima tratados, refere-se à dificuldade que aqueles contrários à institucionalização tinham de criticar esta prática corrente, pois, conforme exposto no início deste estudo, soa contraditório rebater uma prática cujo embasamento está na proteção dos 
menores em situação irregular. Os críticos à imposição incondicional da guarda compartilhada encontram a mesma dificuldade, pois é difícil sustentar a contrariedade a uma modalidade de guarda que está baseada nos Princípios da Igualdade de Gênero, da Isonomia Parental e do Melhor Interesse da Criança e do adolescente, e que, portanto, atende os direitos dos genitores e dos filhos.

O paralelo apresentado não visa equiparar a imposição da guarda compartilhada à Doutrina da Situação Irregular, em especial à institucionalização dos menores em situação irregular, tampouco apresentar posição contrária a esta modalidade de guarda, mas mostrar que existem elementos comuns que conduzem à necessidade de avaliar melhor se, efetivamente, a solução dada pelo artigo 1.584 , inciso II, $\$ 2^{\circ}$ do Código Civil, alterado pela Lei 13.058/2014, vai, em todos os casos, ao encontro do Princípio do Melhor Interesse da Criança e do Adolescente, ou se ele precisa ser revista.

\section{CONCLUSÕES}

Toda a problemática que remete ao paralelo com a Doutrina da Situação Irregular está na redação do artigo 1.584, inciso II, §2º do Código Civil alterada pela Lei 13.058/2014 que coloca a guarda compartilhada como regra no ordenamento jurídico brasileiro - o que parece ser correto - e determina sua imposição judicial independentemente da existência de um ambiente belicoso entre os genitores onde o diálogo e a possibilidade de composição das questões relativas aos filhos são muito difíceis - o que parece ser incorreto.

Sendo assim, a guarda compartilhada representa um avanço frente à guarda unilateral, sendo a modalidade que melhor respeita os Princípios da Igualdade de Gênero, da Isonomia Parental e, em tese, o Princípio do Melhor Interesse da Criança e do Adolescente.

Com relação aos Princípios da Igualdade de Gênero e da Isonomia Parental, o respeito é objetivo, pois esta modalidade evita que a guarda seja concedida apenas a um dos genitores, na maioria dos casos à mãe em função da cultura do mito do amor materno (resolvendo a questão de gênero) e permite o pleno exercícios do poder familiar por ambos os pais que, apesar da imutabilidade legal, é significativamente afetado na guarda unilateral (resolvendo a questão da isonomia parental).

O problema está na atenção ao Princípio do Melhor Interesse da Criança e do Adolescente, cujo respeito é subjetivo e, portanto, não admite generalizações, devendo o juiz, com o auxílio de uma equipe multidisciplinar e em atenção à legislação civil, ao Estatuto da 
Criança e do Adolescente e aos direitos fundamentais da população infantojuvenil (que prevalecem sobre os dos adultos e estão assegurados pela Constituição Federal e Convenção Internacional dos Direitos da Criança), verificar, independentemente da redação do artigo 1.584, inciso II, $\S 2^{\circ}$ do Código Civil, se, no caso concreto, a imposição da guarda compartilhada é a medida adequada. Ainda, diante do o "aspecto adjetivo" deste princípio (LAURIA, 2003, p. 62), cabe ao juiz, independentemente da modalidade de guarda determinada, garantir que seu exercício será feito em atenção ao melhor interesse dos filhos, visto sob a perspectivas destes e não dos genitores.

Os defensores da imposição da guarda compartilhada mesmo sem o consentimento e a harmonia entre os genitores sustentam que, ao estabelecer o exercício conjunto do poder familiar, fazendo com que as decisões relativas aos filhos passem a ser tomadas de forma conjunta, fazendo com que os genitores tenham que, necessariamente, deixar as desavenças de lado para conseguir dialogar e decidir todas as questões relativas aos filhos.

Contudo, como bem observado por Jose Carlos Teixeira Giorgis, "a guarda compartilhada não será o remédio milagroso para a cura dos distúrbios familiares” (2015, p. 14) e pode haver casos que, em face da grande mágoa e ressentimento que envolveram o término da relação, os genitores não consigam separar conjugalidade de parentalidade e, consequentemente, ter o diálogo necessário para exercer harmoniosamente a guarda e o poder familiar. Pior ainda, esta incapacidade, somada à necessidade de comunicação, pode provocar um acirramento do litígio e da disputa pelo exercício do poder familiar, o que acabará tendo reflexos negativos nos filhos.

Se intenção é estabelecer a guarda compartilhada como regra, devendo ser imposta inclusive quando há litígio entre os genitores, conforme destacado pela Ministra Nancy ao julgar REsp no 1251000 / MG, é imprescindível um “intenso trabalho de todos os envolvidos para evitar a frustração do intento perseguido, cabendo ao Estado-Juiz agir na função de verdadeiro mediador familiar, interdisciplinar". Caso contrário, o Estado estará fazendo com as crianças envolvidas em conflitos familiares o mesmo que fez com os menores em situação irregular, quando os colocava em um abrigo sem dar a assistência adequada, tampouco proporcionar às suas famílias condições para que pudessem atender minimamente as necessidades dos filhos de modo que não precisassem ser institucionalizados.

\section{REFERÊNCIAS}


AMIN, Andréa Rodrigues. In: ANDRADE, Kátia Regina Andrade Maciel (Coord). Curso de direito da criança e do adolescente: aspectos teóricos e práticos. 8. ed. rev., atual. e ampl. São Paulo: Saraiva, 2015.

BADINTER, Elizabeth. Um amor conquistado: o mito do amor materno. Rio de Janeiro: Nova Fronteira, 1995.

BRASIL. Código Civil (1916). Lei 3.071 de $1^{\circ}$ de janeiro de 1916. Disponível em: <http://www.planalto.gov.br/ccivil_03/leis/L3071.htm >. Acesso em: 10 mai. 2017.

BRASIL. Constituição (1988). Constituição da República Federativa do Brasil de 1988.

Disponível

em:

http://www.planalto.gov.br/ccivil_03/constituicao/constitui\%C3\%A7ao.htm >. Acesso em: 10 mai. 2017

BRASIL. Código Civil (2002). Lei 10.046 de 10 de janeiro de 2002. Disponível em: < http://www.planalto.gov.br/ccivil_03/leis/2002/L10406.htm\#art2045 >. Acesso em: 10 mai. 2017.

BRASIL. Lei 8.069, de 13 de julho de 1990. Disponível em: < http://www.planalto.gov.br/ccivil_03/leis/L8069.htm >. Acesso em: 10 mai. 2017.

BRASIL. Lei n. 11.698 de 13 de junho de 2008. Disponível em: < http://www.planalto.gov.br/ccivil_03/_ato2007-2010/2008/lei/111698.htm >. Acesso em: 10 mai. 2017

BRASIL. Lei n. 13.058, de 22 de dezembro de 2014. Disponível em: < http://www.planalto.gov.br/ccivil_03/_ato2011-2014/2014/lei/113058.htm >. Acesso em: 10 mai. 2017.

BRASIL. Superior Tribunal de Justiça. Recuso Especial n. 466.343-1/SP. Relatora: Min. Nancy Andrighi. Brasília 23 de ago. de 2011. Disponível em: < http://www.stj.jus.br/SCON/jurisprudencia/doc.jsp?livre=guarda+compartilhada\&b=ACOR\& $\mathrm{p}=$ true $\& \mathrm{l}=10 \& \mathrm{i}=19>$. Acesso em 11 de maio de 2017.

BRASIL. Decreto 99.710, de 21 de novembro de 1990. Disponível em: < http://www.planalto.gov.br/ccivil_03/decreto/1990-1994/d99710.htm >. Acesso em: 10 mai. 2017.

RIO GRANDE DO SUL. Tribunal de Justiça. Apelação Cível 70059147280. Relator: Des. Sérgio Fernando de Vasconcellos Chaves. Porto Alegre, 14 de abr. de 2014. Disponível em: 
http://www.tjrs.jus.br/busca/search?q=70059147280\&proxystylesheet=tjrs_index\&client=tjrs _index \&filter $=0 \&$ getfields $=* \&$ aba $=$ juris \&entsp $=$ a_politica-

site $\& w c=200 \& w c \_m c=1 \& o e=U T F-8 \& i e=U T F-$

$8 \& u d=1 \&$ sort=date $\% 3 \mathrm{AD} \% 3 \mathrm{AS} \% 3 \mathrm{Ad} 1 \&$ as_qj=\&site=ementario\&as_epq=\&as_oq=\&as_eq =\&as_q=+\#main_res_juris $>$. Acesso em 11 de maio de 2017.

BUÑOL, Miguel Cillero. O interesse superior da criança no marco da convenção internacional sobre os direitos das crianças. In: BELOFF, Mary; MÉNDEZ, Emílio Garcia (Org.). Infância, lei e democracia na América Latina: análise crítica do panorama legislativo no marco da Convenção Internacional dos Direitos da Criança (1990-1998). Blumenau: EDIFURB, 2001.

COSTA, Ana Paula Motta. Os adolescentes e seus direitos fundamentais. Porto Alegre: Livraria do Advogado, 2012.

GIORGIS, Jose Carlos Teixeira. In: COLTO, Antônio Carlos; DELGADO, Mário Luiz (Coord.). Guarda compartilhada. 2.ed. rev. e atual. Rio de Janeiro: Forense; São Paulo: Método: 2016.

GRISARD FILHO, Waldyr. Guarda compartilhada. 8.ed. atual. e ampl. São Paulo: Revista dos Tribunais, 2016.

KREUZ, Sérgio Luiz. O direito a convivência familiar da criança e do adolescente: direitos fundamentais, princípios constitucionais e alternativas ao acolhimento institucional. Curitiba: Juruá, 2012.

LAURIA, Flavio Guimarães. A regulamentação de visitas e o princípio do melhor interesse da criança. 2. tir. Rio de Janeiro: Lumen Juris, 2003.

MACHADO, Marta de Toledo. A proteção constitucional de crianças e adolescentes e os direitos humanos. Barueri: Manole, 2003.

MADALENO, Rolf. Curso de direito de família. 5. ed. rev. atual. e ampl. Rio de Janeiro: Forense, 2013.

MAZZUOLI, Valerio de Oliveira. O controle jurisdicional da convencionalidade das leis. 2. ed. rev., atual. e ampl. São Paulo: Editora Revista dos Tribunais, 2011. vol. IV.

MÉNDEZ, Emílio Garcia. Infância e cidadania na América Latina. São Paulo: Hucitec/Instituto Ayrton Senna, 1998.

MOURA, Mário Aguiar. Guarda de filho menor. In: Ajuris, n. 19. Porto Alegre, jul. 1980. 
PEREIRA, Rodrigo da Silva. Princípio fundamentais norteadores do direito de família. 2. ed. São Paulo: Saraiva, 2012.

PEREIRA, Tânia da Silva. Direito da criança e do adolescente: uma proposta interdisciplinar. 2. ed. ver. e atual. Rio de Janeiro: Renovar, 2008.

PIOVESAN. Flavia. Direitos Humanos e o Direito Constitucional Internacional. 7. ed. Saraiva: 2006.

RAMOS, Patrícia Pimentel de Oliveira Chambers. Poder familiar e guarda compartilhada: novos paradigmas do direito de família. 2. ed. São Paulo: Saraiva, 2016.

RIZZINI, Irma. O elogio científico - a construção do "menor" na prática jurídica". In: RIZZINI, Irene (Org.). A criança no brasil hoje: desafio para o terceiro milênio. Rio de Janeiro: Editora Universitária Santa Úrsula, 1993.

ROSA, Conrado Paulino da. Nova Lei da Guarda Compartilhada. São Paulo: Saraiva, 2015.

SILVA, Marcos Alves da. Do pátrio poder à autoridade parental. Rio de Janeiro: Renovar, 2002.

TEPEDINO, Gustavo. A disciplina da guarda e da autoridade parental na ordem civil-constitucional. In: Anais do IV congresso brasileiro de direito de família: afeto, ética, família e o novo código civil brasileiro. IBDFAM. Belo Horizonte: Del Rey, 2004. 